\title{
A correção de resumos acadêmicos: a monitoria de disciplina como atividade de mediação da (re)escrita
}

\author{
Maíra Avelar* \\ Beatriz Graça** \\ André Lisboa*** \\ Hayat Pinheiro****
}

\begin{abstract}
Resumo
O objetivo deste artigo é focalizar as estratégias de correção e intervenção textual do discentemonitor em resumos acadêmicos produzidos por discentes da disciplina "Laboratório de Leitura e Escrita de Textos Acadêmicos", verificando se, de fato, a monitoria de disciplina contribui para a orientação e mediação da reescrita de textos. Ancorando-nos em estudos sobre o gênero textual resumo, bem como numa categorização de intervenções textuais, que variam de intervenções resolutivas a interativas, comparamos duas correções de resumos acadêmicos que compõem o nosso banco de dados: uma, realizada de maneira individual, por uma discente que não discutiu sobre o processo de correção e mediação da escrita de gêneros acadêmicos; e outra, realizada por dois discentes que já tinham passado pelo processo de atuarem como monitores e, assim, de discutir com a professora orientadora, ao longo de sua atuação, sobre as possibilidades e os limites de intervenção num texto cuja escrita e a palavra final é do discente-autor. A partir da comparação das duas correções, foi possível constatar que o trabalho de formação de corretores, um dos aspectos desenvolvidos na formação de monitores, revela-se como um processo relevante na formação de futuros professores de Língua Materna que, dentre outras tarefas, precisam atuar como corretores, ou seja, interlocutores e mediadores da (re)escrita do texto de discentes, seja nos Ensinos Fundamental e Médio, seja no Ensino Superior.
\end{abstract}

Palavras-chave: Correção textual. Reescrita textual. Resumo acadêmico. Monitoria de disciplina.

\section{The correction of academic summaries: the academic monitoring as writing rewriting mediation activity}

\begin{abstract}
The aim of this paper is to analyze the strategies used by the assistant-student to correct the author-student's text, in order to verify the positive contributions of the course "Reading and Writing Lab" to the instructions of rewriting the text genre summary. Based on the studies of the text genre summary and on textual interventions that were resolutive and interactive, we aim to compare two corrections of students texts found at our database: one made individually by a student that did not went through the textual correction and writing mediation training and another made by two students that already had experience in academic monitoring. Through the comparison of the corrections, we verified that the work developed in the academic monitoring is relevant in the professional formation of language teachers because it prepares them to work as interlocutors and mediators in the writing and rewriting process at the classroom.
\end{abstract}

Keywords: Textual correction. Writing and rewriting. Academic summary. Academic monitoring.

Aceito: $20 / 02 / 2019$

Recebido: 12/07/2019

\footnotetext{
* Universidade Estadual do Sudoeste da Bahia (UESB). Professora Adjunta do DELL e membro do quadro efetivo do PPGLin..

** Universidade Estadual do Sudoeste da Bahia (UESB). Mestranda em Linguística.

*** Universidade Estadual do Sudoeste da Bahia (UESB). Mestrando em Linguística.

**** Universidade Estadual do Sudoeste da Bahia (UESB). Doutoranda em Linguística.
} 


\section{Introdução}

A escrita acadêmica e, consequentemente, o ensino e a aprendizagem de gêneros acadêmicos fazem parte do conjunto de habilidades e saberes necessários ao futuro professor de Língua Materna (LM) que ingressa na universidade. Pretendemos, então, discutir o processo de ensino e aprendizagem de um gênero acadêmico específico, o resumo, num contexto de monitoria da disciplina "Laboratório de Leitura e Escrita de Textos Acadêmicos", ministrada no primeiro semestre do curso de Letras de uma instituição de Ensino Superior pública.

A disciplina de Laboratório de Leitura e Escrita de Textos Acadêmicos compõe o quadro de disciplinas da grade curricular do curso de Letras da universidade pública de onde coletamos o material analisado no presente artigo. A disciplina em questão é ministrada no primeiro semestre do curso. Dessa forma, com exceção de poucos alunos que cursam uma segunda graduação, os discentes que a frequentam não possuem contato prévio com os gêneros acadêmicos, objetos de estudo da disciplina. Na ementa, é proposto que se trabalhem os gêneros resumo e resenha acadêmicos, bem como os mecanismos de textualidade responsáveis pela coesão e coerência de um texto.

No nosso entendimento, a disciplina funciona como uma "porta de entrada" para o domínio discursivo acadêmico, bem como para o saber-dizer e, consequentemente, o saber-fazer próprios desse domínio discursivo. Segundo Marcuschi (2008), os gêneros pertencentes a uma determinada esfera discursiva possuem correlação com as práticas sociais próprias da esfera em questão. Nesse sentido, o trabalho de monitoria, discutido mais detalhadamente ao longo deste texto, configura-se como uma interlocução e mediação da escrita, em que discentes do curso de Letras, de semestres mais avançados, têm a oportunidade de atuar como corretores e mediadores do processo de reescrita de texto. Sendo assim, é um processo em que os discentes também refletem e, ao ensinarem, aprendem sobre a atividade de intervenção no texto do outro, aprimorando, assim, a habilidade de atuarem como corretores de texto, o que também é relevante para a formação de futuros professores de LM.

\section{0 ensino e a aprendizagem de gêneros acadêmicos na formação de professores de LM}

Conforme argumenta Antunes (2015), a imagem que se projeta sobre a figura do professor tem sido reformulada, isto é, já não se pensa no professor como aquele que detém todo o conhecimento, mas sim como aquele que não pode deixar de ser um aprendiz. Desse modo, a formação inicial de professores de LM é um processo fundamental no fazer pedagógico, pois é sendo aluno que se aprende a ser professor. Nesse sentido, é muito importante que a profissionalização docente esteja atrelada às mudanças que acontecem no âmbito escolar e às perspectivas e concepções que envolvem as práticas pedagógicas. Dessa forma, levando em conta a ideia de que o professor de LM deve ensinar a ler e a escrever por meio de gêneros textuais que circulam socialmente, a formação docente precisa privilegiar uma construção de saberes que faça os futuros professores assumirem uma postura crítica e reflexiva em relação ao texto.

De acordo com Marcuschi (2008), não é possível dissociar o ensino de línguas dos textos orais e escritos. Nesse sentido, quando se pensa na formação de professores, a disciplina Laboratório de Leitura e Escrita de Textos Acadêmicos é fundamental, uma vez que ela se funda em uma concepção de língua na qual a maior preocupação recai nos processos de reescrita e autoavaliação das produções textuais, e não, necessariamente, no produto.

Ainda segundo o autor (MARCUSCHI, 2008), há muito mais gêneros na escrita do que na fala, pois, na modalidade escrita, dispõe-se de uma maior diversidade de ações linguísticas. Na perspectiva da formação docente, o material utilizado na disciplina possui um caráter fortemente didático, ou seja, 
não é direcionado para o pesquisador em Linguística Textual, por exemplo, mas sim ao aluno, que, nesse caso, se configura como o futuro professor de LM.

A partir da escrita e reescrita de textos, mais especificamente, de resumos, os alunos têm acesso aos padrões, funções e objetivos sociocomunicativos do gênero. Além disso, eles têm a oportunidade de exercitar as práticas discursivas e docentes que estarão presentes na futura esfera profissional, como a correção de produções textuais, por exemplo.

Os objetivos da disciplina dialogam com a proposição de Marcuschi (2008): de acordo com ele, quando se domina um gênero textual, domina-se "uma forma de realizar linguisticamente objetivos específicos em situações sociais particulares" (MARCUSCHI, 2008, p. 154). No entanto, o trabalho em Laboratório de Leitura e Escrita de Textos Acadêmicos consiste, também, em desmistificar algumas noções dos alunos acerca do gênero resumo, uma vez que, tal como discutiremos mais detalhadamente adiante, chegam à universidade com ideias de senso comum, como, por exemplo, a de que elaborar um resumo consiste, apenas, em reduzir o tamanho do texto-base a ser resumido.

\section{0 gênero resumo na esfera de atividade acadêmica}

Para instanciar a discussão a respeito do gênero resumo na esfera de atividade acadêmica, partimos da noção de gênero textual proposta por Marcuschi (2008). O autor estabelece que a noção de gênero textual refere-se aos textos materializados em situações comunicativas recorrentes. Os gêneros textuais são, portanto, os textos encontrados em nossa vida diária. Conforme descreve o autor, esses textos "apresentam padrões sociocomunicativos característicos definidos por composições funcionais, objetivos enunciativos e estilos comumente realizados na interação de forças históricas, sociais, institucionais e técnicas" (MARCUSCHI, 2008, p. 155).

Ele admite, em consonância com Bakhtin (1979 apud MARCUSCHI, 2008, p. 155), que todas as atividades humanas estão relacionadas ao uso da língua, que se efetiva através de enunciados orais e escritos "concretos e únicos, que emanam dos integrantes de uma ou de outra esfera da atividade humana”. Sendo assim, Marcuschi (2008) defende que não se pode tratar do gênero do discurso de forma independente de sua realidade social e de sua relação com as atividades humanas. A partir dessas considerações a respeito de gênero textual, discorreremos, de maneira específica, a respeito do gênero textual resumo, um dos gêneros textuais em circulação na esfera de atividade acadêmica.

Matencio (2002) afirma que a ação de resumir está envolvida na atividade de leitura. Para a autora, ler um texto implica resumir/sumarizar, mesmo que não demande a escrita de outro texto. Van Dijk (1988 apud MATENCIO, 2002) trata desse processo ao descrever as macrorregras de sumarização. Essas macrorregras, descritas pelo autor, podem ser consideradas como estratégias através das quais o leitor sumariza o texto, ao reter informações que considere centrais. Elas envolvem estratégias de apagamento, em que há seleção de proposições relevantes, e estratégias de substituição, em que se dá a generalização e a construção. A generalização implica substituição de um conjunto de nomes de seres, de propriedades e de ações por um nome, propriedade ou ação mais geral. Já a construção caracteriza-se pela substituição de uma sequência de proposições por uma proposição que dela é deduzida.

De acordo com Matencio (2002), quando a ação de resumir um texto, além de implicar leitura, envolve retextualização, há produção do gênero resumo. Matencio (2003) propõe que a retextualização envolve a produção de um novo texto a partir de um ou mais textos-base. Isso significa que o sujeito trabalha sobre as estratégias linguísticas, textuais e discursivas identificadas no texto-base para, assim, projetá-las, tendo em vista uma nova situação de interação, portanto, um novo enquadre e um novo quadro de referência. Em outras palavras, na concepção adotada por Matencio (2003), 
retextualizar implica redimensionar a projeção de imagens entre interlocutores, de seus papéis sociais e comunicativos, dos conhecimentos partilhados, das motivações e intenções, do espaço e do tempo de produção/recepção, enfim, de atribuir um novo propósito à produção textual.

Nas práticas acadêmicas, conforme esclarece Matencio (2003), ensinar o aluno a resumir é uma forma de inseri-lo no universo de produção dessas práticas, é possibilitar que ele produza enquadres que considerem as regularidades linguísticas, textuais e discursivas, em um movimento que engloba tanto um saber-fazer, ou seja, a apropriação de conceitos e procedimentos acadêmicocientíficos, quanto um saber-dizer, isto é, os modos de referência e de textualização dos saberes. De acordo com a autora, entender a relação entre saber-fazer e saber-dizer envolve a compreensão da especificidade do discurso científico e sua articulação com os discursos de transmissão de conhecimento (discurso de divulgação científica e discurso didático), seja em relação aos traços que caracterizam a dimensão pragmática dos textos que configuram esses diferentes discursos, seja no que diz respeito ao seu modo de configuração linguística.

Para tratar, de maneira mais detalhada, do gênero resumo, na esfera de atividade acadêmica, retomaremos a proposta de Matencio (2002), a respeito dos tipos de resumos produzidos nessa esfera de atividade. A autora descreve três tipos de resumos e menciona um quarto tipo.

Segundo Matencio (2002), o primeiro tipo de resumo vincula-se estritamente apenas a algumas das macroestruturas do texto-base. A autora cita como exemplos desse tipo de resumo aqueles encontrados no interior de artigos, dissertações e teses, que têm como função integrar a discussão do estado da arte ao objeto de estudo daquele que retextualiza. O segundo tipo é constituído por aqueles resumos que, integrados a um texto acadêmico, possuem a função central de descrever o modo de realização do trabalho acadêmico, e não necessariamente sua estrutura. São exemplos desse tipo de resumo, conforme sinaliza a autora, os résumés ou abstracts do trabalho científico. O terceiro tipo de resumo, descrito por Matencio (2002), é encontrado nas práticas acadêmicas e está envolvido no processo de elaboração da pesquisa. Esse resumo possui a função de mapear um campo de estudos a ser desvendado pelo retextualizador e também possui função de servir como referência para consulta em momentos posteriores da pesquisa. A autora ressalta que, frequentemente, a elaboração desse tipo de resumo implica um alto grau de subordinação ao textobase, ou seja, às suas macroposições.

A autora menciona, ainda, um quarto tipo de resumo, os resumos que são produzidos na escola, cuja função primordial é indicar a compreensão do texto-base. Ao discorrerem a respeito desse tipo de resumo, Guimarães Silva e Da Mata (2002) afirmam que caracterizá-lo como um gênero da esfera de atividade acadêmica, decorrente das atividades de retextualização dos mais variados gêneros textuais (artigos, ensaios, teses, monografias, capítulos de livros etc.), implica, necessariamente, considerar as operações mentais de compreensão de um texto-fonte envolvidas nesse processo, que corresponderiam às macrorregras propostas por Van Dijk.

Em consonância com a proposta de Matencio (2002), para Guimarães Silva e Da Mata (2002), o resumo escolar - e, acrescentamos, também o resumo acadêmico solicitado por professores das mais variadas disciplinas - funciona, muitas vezes, como uma atividade de avaliação de leitura. Em outras palavras, na concepção adotada pelas autoras, esse tipo de resumo constitui uma prática discursiva da comunidade acadêmica que responde a uma demanda de atividades de ensino/ aprendizagem: atividade de leitura e, por extensão, de produção de texto. Nessa perspectiva, é possível compreender a função e o uso social desse tipo de resumo que envolve verificar se o alunoprodutor possui competências/habilidades necessárias para o que lhe é proposto: ler/compreender e registrar linguisticamente tal compreensão. Portanto, de acordo com as autoras, a função/finalidade do gênero regula o propósito discursivo do produtor que visa a apresentar, de forma clara, as informações consideradas relevantes, em função dos objetivos de leitura. 
Esses exemplos de tipos de resumos produzidos na esfera de atividade acadêmica, descritos por Matencio (2002), demonstram o quanto varia a configuração de um resumo, em decorrência da variação que se tem da ação de resumir e das diversas funções que essa ação pode receber nas práticas discursivas. Além disso, de acordo com a proposição da autora, esses exemplos parecem indicar a existência de um continuum entre os diferentes tipos de resumo, que iriam daqueles que mais se aproximam do texto-base (cuja função primordial é a de registrar a leitura) até aqueles que guardam apenas referências do texto-base (que podem ser utilizados para uma nova produção de texto).

\subsection{A percepção dos discentes a respeito do gênero resumo}

Os alunos do primeiro semestre do curso de Letras, ao estabelecerem um primeiro contato com a disciplina Laboratório de Leitura e Escrita de Textos Acadêmicos, apresentam algumas representações dos gêneros acadêmicos, especialmente do gênero resumo, que são constituídas por noções de senso comum e por regras presentes em manuais de produção textual da educação básica.

A primeira representação muito comum de resumo, reproduzida pelos alunos, indica que todo e qualquer resumo deve reproduzir todas as ideias do texto-base, ou seja, é esperado que o aluno faça uma leitura parafrástica do texto-base, sem que altere seu conteúdo informacional e semântico, gerando, portanto, um trabalho de "colagem" de informações (GUIMARÃES SILVA; DA MATA, 2002). Nesse caso, quando é demandado do discente que produza um resumo, ele focaliza, apenas, a estratégia de apagamento e acaba não lançando mão de outras macrorregras como a sumarização, a substituição e a generalização, que implicam escolhas subjetivas, além de demonstrarem a interpretação e compreensão, por parte do discente-autor, das ideias do texto-base, ainda que essa compreensão esteja fortemente correlacionada às ideias contidas no texto-base.

Nesse sentido, os discentes costumam reproduzir, no início do curso de Letras, uma concepção de resumo que é fruto de prescrições normativas do senso comum que reduzem o gênero à simples ideia de condensação de informações. Consequentemente, além de não fazerem uso de outras metarregras de sumarização, também produzem resumos que não cumprem as funções sociocomunicativas do gênero. A fim de ampliar a visão dos discentes a respeito do resumo, para que eles possam compreender que a escrita de um gênero - e a futura discussão que realizarão em sala de aula, como professores precisa ser feita levando-se em consideração o contexto de produção e circulação daquele gênero, seus propósitos sociocomunicativos, sendo que isso reflete, consequentemente, na escolha de estratégias textuais e dos modos de dizer do discente-autor do resumo. Nas palavras da professora ${ }^{1}$ da disciplina de Laboratório:

O primeiro desafio que enfrento, ao solicitar a produção de resumos acadêmicos, ou de qualquer outro gênero da esfera acadêmica, é o de demonstrar para os alunos que, ao contrário do que eles trazem da escola, a produção escrita de um gênero não se resume a seguir uma fórmula, uma receita de bolo. $\mathrm{O}$ autor do resumo precisa demonstrar sua compreensão do texto-base, guiando o leitor em relação aos movimentos feitos no textobase, mas produzindo um texto autônomo, que seja capaz de ser interpretado sem que o leitor precise recorrer ao texto-base.

Verificamos, a partir dessa fala, que a professora aponta o fato de que a escola, nos moldes tradicionais, desencoraja o aluno a se colocar como sujeito de suas próprias produções, limitando-se a reproduzir fórmulas para escrever, ao invés de produzirem um texto em que se leve em consideração a compreensão do leitor e os aspectos sociocomunicativos que envolvem qualquer produção textual.

1 Todos os trechos de entrevista fazem parte do nosso banco de dados. Por questões éticas, optamos por manter o anonimato dos sujeitos entrevistados. 
Entretanto, consideramos que, dada a predominância da solicitação de resumos cuja função didática é verificar a compreensão do discente a respeito de um determinado assunto, esses discentes acabam por assumir que o professor, que já teria acesso ao texto-base, é o interlocutor e que, portanto, não há necessidade de contextualizar ou relatar os movimentos que o autor do texto-base realiza. Coloca-se, então, como mais um desafio, a questão de contornar a artificialização da produção dos resumos.

\section{Mediação da reescrita de e por professores em formação: o trabalho da monitoria}

Um dos recursos oferecidos aos discentes cursantes da disciplina de Laboratório de Leitura e Escrita de Textos Acadêmicos é obter um atendimento individualizado e sanar dúvidas de produção escrita na monitoria de disciplina. Como a disciplina em questão possui um caráter predominantemente prático, uma vez que exige que os alunos produzam textos e sejam proficientes na escrita acadêmica, isso requer um processo de reflexão e reescrita do próprio texto. Nesse sentido, o trabalho dos monitores tem como objetivo contribuir para um desenvolvimento mais produtivo da disciplina, já que o trabalho orientado de monitoria disponibiliza um espaço de diálogo que permite que o aluno, com ajuda dos monitores, reflita sobre o seu próprio processo de escrita e interpretação de textos. Dessa forma, nota-se que há um melhor aproveitamento e satisfação dos alunos em relação à disciplina, visto que a monitoria oferece a oportunidade de debater sobre questões textuais com alunos de Letras mais experientes.

A atividade de monitoria em disciplinas de texto é relevante, ainda, na formação teórica e prática do aluno de Letras, pois permite que tanto o discente do primeiro semestre quanto os monitores da disciplina refinem os conhecimentos linguísticos e lidem, na prática, com atividades fundamentais na realidade profissional de futuros professores de LM, como a correção e orientação de reescrita, por exemplo. O trabalho de monitoria, descrito em etapas a seguir, foi realizado em 2016, direcionado a turmas de primeiro semestre dos cursos de Letras Modernas e Vernáculas de uma instituição de Ensino Superior pública.

As tarefas desempenhadas pelos alunos-monitores tinham como foco fornecer um suporte aos alunos da disciplina, oferecer um atendimento individual nas dependências da universidade, auxiliar na elaboração de atividades de (re)escrita, bem como na interpretação dos textos teóricos da disciplina, orientar quanto às dúvidas das matérias ministradas em aula, ministrar aulas de revisão com a supervisão direta da professora orientadora e participar dos processos de correção de atividades e avaliações.

As atividades de reescrita são entendidas como parte do processo de escrita e, durante os atendimentos, representavam, para os discentes do primeiro semestre, um momento de reflexão e análise a respeito do que eles mesmos escreveram, uma vez que, dada a necessidade de reescrever um texto, o discente-autor precisa (re)avaliar os objetivos da sua produção e tomar decisões acerca da forma como o texto deverá ser reformulado (ANTUNES, 2015). Ao mesmo tempo, do ponto de vista do discente-monitor, também é preciso pensar em estratégias de intervenção em textos que apresentam problemas de escrita e precisam ser reescritos.

De modo mais específico, o planejamento das atividades de monitoria envolvia as seguintes etapas: i) leituras teóricas orientadas; ii) seleção e organização orientada de material; iii) acompanhamento de aula; iv) orientação dos alunos; v) reuniões de planejamento. Na primeira etapa, com a indicação da professora orientadora, foi realizada a leitura dos materiais teóricos que serviam de base para as disciplinas, para que se pudesse oferecer aos alunos um atendimento mais qualificado. Já na segunda, foi efetuada a organização do material didático utilizado pela professora. Esse material consistia em uma apostila com conceitos teóricos, elaborada pela própria professora da disciplina, resultante de 
uma condensação de livros voltados à teorização e ao ensino e aprendizagem dos gêneros acadêmicos e atividades sobre gênero, texto e textualidade. Os monitores, ainda, auxiliavam na seleção dos textosbase para as produções textuais dos discentes da disciplina de Laboratório, de acordo com as áreas de interesse de cada curso.

Nos acompanhamentos de aula, terceira etapa do trabalho de monitoria, os monitores assistiam a algumas aulas da disciplina, voltadas à orientação para a reescrita de textos a ser realizada na monitoria, no intuito de observar a dinâmica da sala de aula do Ensino Superior. Com isso, foi possível aos discentes-monitores compreenderem melhor o funcionamento da disciplina, a partir de um olhar externo de quem não mais a cursava, e, consequentemente, compreenderem o papel que poderiam desempenhar como discentes-monitores e futuros professores de LM.

A quarta etapa, por sua vez, foi o momento de lidar com os alunos de maneira mais individualizada por meio de plantões previamente organizados pela orientadora, nos quais era realizada a leitura, com os discentes-autores, de suas produções textuais. A partir disso, os discentes-monitores dialogavam com os discentes-autores a respeito de eventuais dúvidas ou problemas decorrentes do processo de escrita. Em seguida, os discentes-monitores orientavam as atividades de reescrita, nas quais os discentes-autores tinham a oportunidade de revisitar seus próprios textos e, desse modo, refletir sobre o seu processo de aprendizagem dos gêneros acadêmicos trabalhados na disciplina de Laboratório. As reuniões de planejamento, quinta etapa das atividades de monitoria, possibilitaram o relato, por parte dos discentes-monitores, de sua experiência como corretores e mediadores de reescrita de textos à professora orientadora. A partir disso, de maneira conjunta, eram planejadas as próximas etapas da disciplina de Laboratório. Nesse sentido, o trabalho de monitoria mostrou-se benéfico não apenas para os discentes, mas também para a professora orientadora, ministrante da disciplina, que teve a oportunidade de reconfigurar algumas etapas do planejamento das aulas, de modo a trabalhar e elaborar, de maneira mais específica, questões relacionadas ao ensino e aprendizagem do gênero em pauta, naquele momento da disciplina, bem como aos gêneros que ainda seriam objeto de ensino e aprendizagem, contemplando, de maneira mais satisfatória, demandas específicas da turma.

\section{0 processo de correção e mediação da reescrita: procedimentos metodológicos e análise de duas intervenções textuais}

\subsection{Procedimentos metodológicos}

Optamos, neste artigo, por focalizar as estratégias de intervenção do discente-monitor no texto do discente-autor, de modo a efetuar correções nos textos dos discentes que apresentaram dúvidas e dificuldades em relação à produção escrita do gênero resumo acadêmico e, por essa razão, buscaram a monitoria da disciplina. Analisaremos, a seguir, duas correções textuais que compõem o nosso banco de dados. A primeira delas foi realizada por uma discente do curso de Letras que não atuou como monitora da disciplina de Laboratório. Já a segunda correção foi realizada por dois discentesmonitores da disciplina.

No intuito de verificar se, de fato, a monitoria de disciplina contribui de maneira positiva para as intervenções textuais realizadas, pretendemos, então, comparar as duas correções: uma, realizada de maneira individual, por uma discente que não discutiu sobre o processo de correção e mediação da escrita de um resumo, e outra, feita por outros dois discentes que, além de terem tido a oportunidade de dialogar entre si, já tinham passado pelo processo de atuarem como monitores e, assim, de discutir com a professora orientadora, ao longo de sua atuação, sobre as possibilidades e os limites de intervenção num texto cuja escrita e palavra final são do discente-autor. 
Foi solicitado, no contexto de sala de aula, que os discentes da disciplina produzissem o resumo de um ensaio filosófico (consultar Anexo) presente no livro Ensaios céticos, de Bertrand Russell. Antes que a produção fosse realizada, a professora ministrante da disciplina solicitou que os discentes buscassem informações sobre o autor do texto e o contexto histórico em que o texto foi publicado, bem como realizou uma leitura coletiva do texto em voz alta. Além disso, a professora solicitou que os discentes se atentassem à produção de um resumo autônomo em relação ao texto-base e relembrou a atividade realizada sobre "atribuição de atos ao autor do texto resumido" (MACHADO, 2004), em que os discentes, após lerem breves textos, tinham que escolher, por escrito, verbos que melhor relatassem as ações contidas no trecho lido anteriormente.

Foi escolhido, então, um resumo realizado no contexto supracitado, para ser corrigido pelos sujeitos selecionados como corretores. Ancoramo-nos em Ribeiro (2017), para categorizar e discutir as intervenções realizadas pelos corretores do resumo. Com base em Serafini (1989) e Ruiz (2011), ${ }^{2}$ Ribeiro (2017) propõe a seguinte categorização para os tipos de intervenção a serem feitas nos textos a serem revisados:

1. Intervenção resolutiva, em que o corretor resolve os problemas que detecta no texto;

2. Intervenção indicativa, em que o corretor marca os problemas que detecta no texto;

3. Intervenção classificatória, em que o corretor utiliza metalinguagem para indicar os problemas que detecta no texto;

4. Intervenção interativa, em que o corretor sugere mudanças e discute aspectos do texto com o autor.

Depreendemos, da categorização apresentada, que a intervenção resolutiva pressupõe menor margem de interação com o autor, mesmo cabendo a ele aceitar ou não as resoluções propostas, enquanto a intervenção interativa pressupõe maior margem de interação e diálogo (ainda que apenas por meio do texto) entre corretor e autor. Por outro lado, as intervenções indicativa e classificatória costumam ser bastante utilizadas no contexto de sala de aula, em que o professor indica problemas no texto do aluno, muitas vezes utilizando metalinguagem (como: falta sujeito na frase) de modo que o aprendiz faça um esforço para compreender e resolver os problemas de escrita. Entretanto, na prática de correção, muitas vezes, a indicação de um problema, sobretudo quando realizada com a utilização de metalinguagem, faz com que o autor do texto não consiga, de fato, modificá-lo, de modo a solucionar o problema indicado, pois, muitas vezes, o autor não sabe o que é ou não consegue identificar “o sujeito da frase”, por exemplo. É necessário, portanto, verificar se o autor do texto possui domínio da metalinguagem utilizada. Do contrário, a correção pode constituir mais um obstáculo a ser transposto, em vez de funcionar como um elemento facilitador para o autor.

\subsection{Análise das correções}

O primeiro excerto de análise corresponde à intervenção realizada pela discente que não atuou como monitora da disciplina e realizou a correção individual do resumo produzido:

2 As referências completas às obras de Serafini e Ruiz podem ser consultadas na obra de Ribeiro (2017). 
Letras Vernáculas

Bertrand Russell, em um dos ensaios do livro "Ensaios Céticos", inicia o texto questionando o porquê das pesscas terem o desejo de aumentar suas rendas. Ele apresenta a tese de que o desejo por riquezas surge com a intenção de impressionar os outros. O gutor fiscorre sua tese) dando exemplos gue a comprovam, pomo a situação de pais que colocam seus filhos em escolas ou universidades boas e caras, afim de que eles tenham distinçōes sociais proporcionadas pelo status da instituição. Russe) faz uma critica à sociedade ao afirmar que uma das grandes paixões humanas é o desejo pela admiração e respeito, que, atualmente, são atrelados aqueles que parecem ser ricos, $\mathrm{p}$ filós ofo conclui konsiderando a possibilidade de haver uma mudança, pelo fato de existirem sociedades divergentes da nossa, em que o dinheiro é visto apenas para osustento, e o valor estaria nos méritos conquistados.

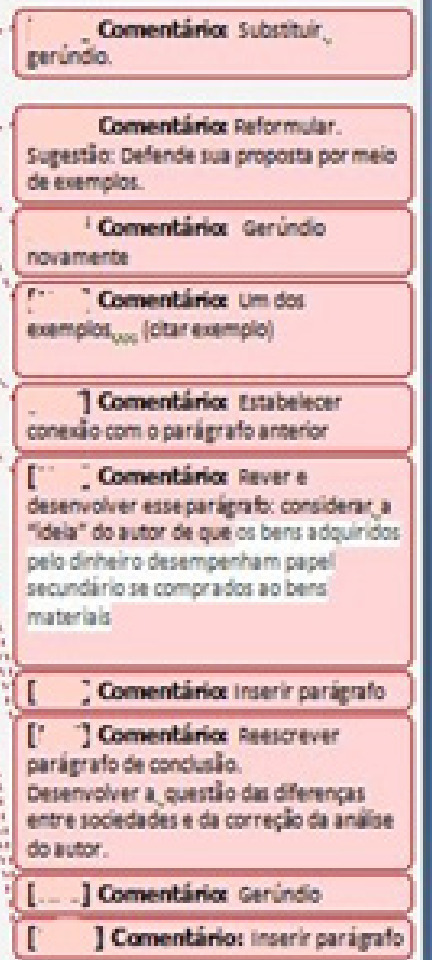

Conforme é possível observar, as correções realizadas podem ser categorizadas como predominantemente indicativas. Ainda que por meio do uso de verbos no infinitivo (e não no imperativo), em 6 dos 10 comentários realizados, a corretora indica, de maneira injuntiva, o que deve ser realizado pelo autor do resumo: "substituir", "reformular", "rever", "fazer conexão", "inserir" (em três comentários) e "reescrever". A corretora também utiliza a correção classificatória, quando apenas sinaliza, em 2 de seus comentários, o gerúndio no texto, sendo que, em 1 deles, há uma injunção: "substituir". Em 2 de seus comentários, a corretora demonstra atenção a aspectos de coerência textual e de argumentatividade, como quando recomenda ao autor "desenvolver esse parágrafo" e explica, em seguida, qual é a ideia a ser desenvolvida. Na mesma linha, ao solicitar ao autor "reescrever parágrafo de conclusão", ela aponta a ideia a ser desenvolvida pelo autor nessa reescrita.

Portanto, de maneira geral, a corretora utiliza modalidades de intervenção no texto que não possibilitam que o autor tenha liberdade de se posicionar como sujeito de sua escrita, uma vez que, com exceção dos 2 últimos comentários discutidos anteriormente, ora a corretora fornece sugestões prontas, que não permitem ao produtor do texto refletir e tomar decisões sobre como reescrever (cf. comentário 2 da imagem), ora indica ao produtor do texto o que fazer, sem, entretanto, estabelecer um diálogo, uma vez que lança mão de injunções, ainda que os verbos utilizados por ela estejam no infinitivo. Além disso, é importante ressaltar que nenhum comentário sobre questões sociocomunicativas do gênero foi realizado: o trabalho de correção focalizou, apenas, questões textuais, mas não indicou ou problematizou aspectos relativos ao gênero resumo.

O segundo excerto de análise corresponde às intervenções realizadas pelos discentes que atuaram como monitores da disciplina e realizaram uma correção a partir das discussões dialogadas sobre o resumo produzido: 


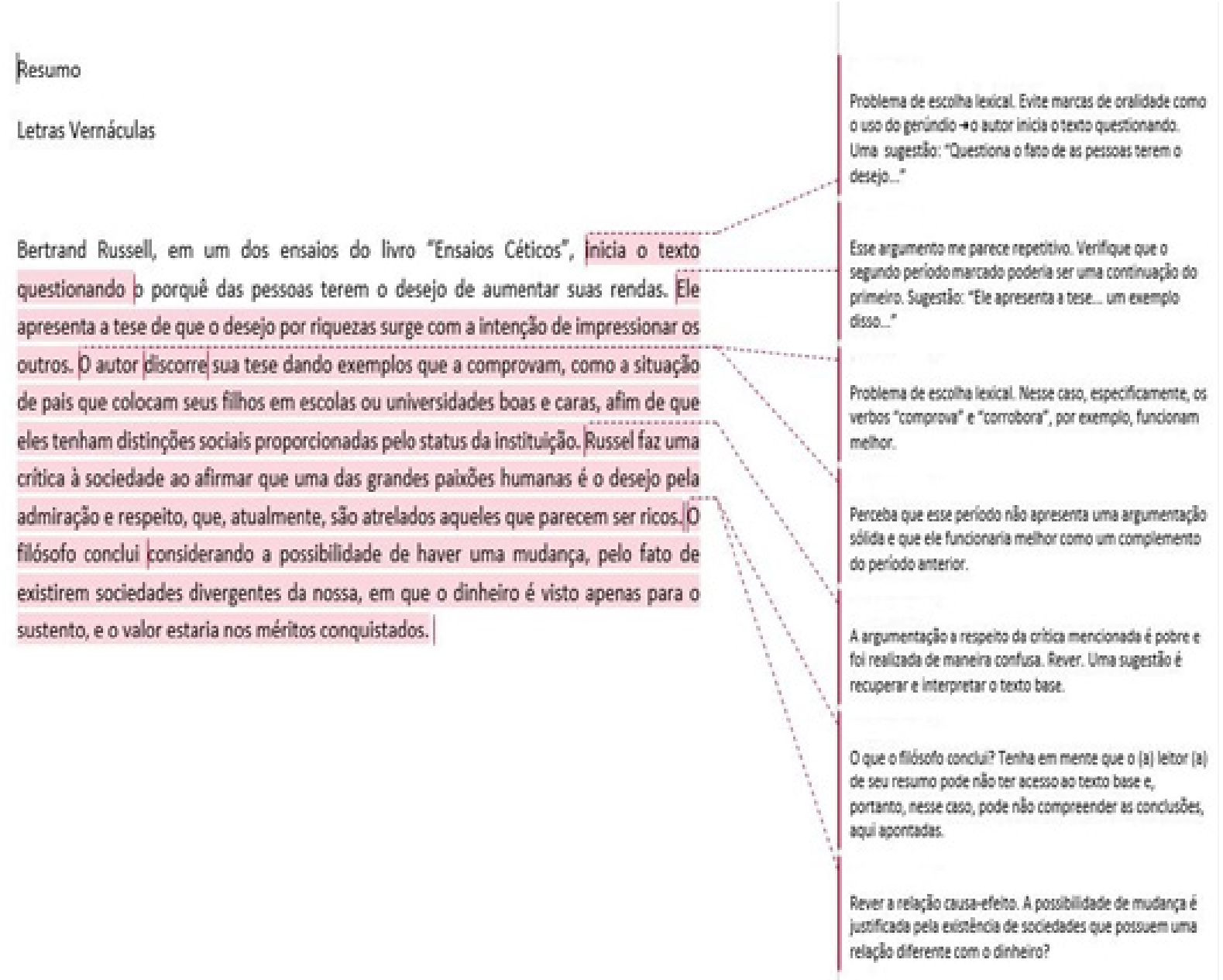

Conforme é possível observar, a correção em questão configura-se como uma intervenção predominantemente interativa: apesar de apresentarem marcas claramente injuntivas, como o uso de verbos no imperativo, todos os comentários realizados podem ser interpretados como uma conversa entre o corretor e o autor do texto, em que o corretor sugere ações mais amplas, tais como: "verifique", "perceba", "tenha em mente" e, no infinitivo, o "rever". Com exceção do último verbo utilizado (que, não por acaso, é o único que se encontra no infinitivo), os demais convidam o autor do resumo a refletir sobre as escolhas metadiscursivas realizadas por ele e, a partir disso, pensar em possibilidades de reescrita do texto. Além disso, quando a intervenção classificatória é utilizada, a metalinguagem (como, por exemplo, "escolha lexical", termo utilizado em dois comentários), os corretores tentam explicar o problema e oferecem sugestões de correção. Entretanto, essa atitude de oferecer sugestões prontas também é passível de questionamento, uma vez que, potencialmente, retira do autor a possibilidade didática de formular, por conta própria, soluções para os problemas encontrados.

Ao compararmos as duas intervenções, é possível verificar que, apesar de os corretores terem optado, em ambas as correções, por utilizar a ferramenta "Inserir comentários", apenas na segunda correção é estabelecido, de fato, um diálogo em que é possível, para o autor do resumo, reavaliar algumas escolhas textuais que prejudicam aspectos amplos de argumentatividade, clareza e, em última análise, o leitor do texto. A própria escolha de verbos utilizados em ambas as correções demonstra isso: enquanto a primeira corretora utiliza verbos relacionados a ações a serem desempenhadas na modificação do texto, os dois outros corretores utilizam verbos que estão relacionados a uma atitude reflexiva, por parte do autor, no sentido de revisitar "o que" e "como" ele está produzindo o texto. A comparação das duas correções indica, então, que o trabalho de formação de corretores, um dos aspectos desenvolvidos no trabalho de monitoria, revela-se como um instrumento relevante na formação de professores de LM, que, dentre outras tarefas, desempenharão o trabalho de atuarem 
como interlocutores e mediadores da (re)escrita do texto de discentes, seja nos Ensinos Fundamental e Médio, seja no Ensino Superior.

\section{Considerações finais}

A partir do relato da atividade de monitoria da disciplina de Laboratório, observamos que a importância do trabalho do monitor para o processo de aprendizagem dos discentes se fundamenta na possibilidade de diálogo, por meio do texto, entre discente-autor e discente-monitor. Nesse sentido, é importante ressaltar que o discente-monitor não atua como autor do texto, mas como um interlocutor qualificado, que realiza intervenções no sentido de fazer com que o discente-autor reoriente a escrita de seu texto, de modo a refinar não apenas questões formais do texto acadêmico, mas, sobretudo, a se atentar para questões sociocomunicativas que envolvem a produção e a leitura/legibilidade de gêneros acadêmicos. Assim, o trabalho de monitoria que relatamos permite que, por meio da escrita, os discentes-autores consigam pensar na produção de resumos acadêmicos de maneira mais ampla, ao mesmo tempo em que possibilita que os discentes-monitores aprendam, na prática, a atuarem no sentido de trabalhar as habilidades dos discentes para a escrita.

\section{Referências}

ANTUNES, Irandé. Aula de Português: encontro e interação. São Paulo: Parábola Editorial, 2015. GUIMARÃES SILVA, Jane Quintiliano; DA MATA, Maria Aparecida. Proposta tipológica de resumos: um estudo exploratório das práticas de ensino da leitura e da produção de textos acadêmicos. Scripta, Belo Horizonte, v. 6, n. 11, p. 123-133, 2 sem. 2002.

MACHADO, Anna Rachel. Procedimentos de inserção de vozes: diferentes formas de menção ao dizer do autor do texto resenhado e de outros autores. In: MACHADO, Anna Rachel. Resumo. São Paulo: Parábola, 2004. p. 44-59.

MARCUSCHI, Luiz Antônio. Produção de texto, análise de gêneros e compreensão. São Paulo: Parábola Editorial, 2008.

MATENCIO, Maria de Lourdes Meirelles. Atividades de (re) textualização em práticas acadêmicas: um estudo do resumo. Scripta, Belo Horizonte, v. 6, n. 11, p. 109-122, $2^{\circ}$ sem. 2002.

MATENCIO, Maria de Lourdes Meirelles. Referenciação e retextualização de textos acadêmicos: um estudo do resumo e da resenha. In: ANAIS DO III CONGRESSO INTERNACIONAL DA ABRALIN. Rio de Janeiro, mar. 2003.

RIBEIRO, Ana Elisa. Revisão de textos e "diálogo" com o autor: abordagens profissionais do processo de produção e edição textual. In: RIBEIRO, Ana Elisa. Em busca do texto perfeito: questões contemporâneas de edição, preparação e revisão textual. Divinópolis: Artigo A, 2017. p. 63-76.

RUSSEL, Bertrand. Ensaios céticos. 2. ed. São Paulo, 1957. 


\section{Anexo}

Na verdade, por que desejamos, quase todos nós, aumentar nossa renda? À primeira vista, pode parecer que desejamos bens materiais. Mas, na verdade, os desejamos principalmente para impressionar o próximo. Quando um homem muda-se para uma casa maior num bairro melhor, reflete que gente "de mais classe" visitará sua esposa, e que alguns pobretões deixarão de frequentar seu lar. Quando manda o filho a um bom colégio ou a uma universidade cara, consola-se das pesadas mensalidades e taxas pensando nas distinções sociais que tais escolas conferem a pais e filhos. Em toda cidade grande, seja na América ou na Europa, casas iguaizinhas a outras são mais caras num bairro que noutro, simplesmente porque o bairro é mais chique. Uma das nossas paixões mais potentes é o desejo de ser admirado e respeitado. No pé em que estão as coisas, a admiração e o respeito são conferidos aos que parecem ricos. Esta é a razão principal de as pessoas quererem ser ricas. Efetivamente, os bens adquiridos pelo dinheiro desempenham papel secundário. Vejamos, por exemplo, um milionário, que não consegue distinguir um quadro do outro, mas adquiriu uma galeria de antigos mestres com auxílio de peritos. $\mathrm{O}$ único prazer que lhe dão os quadros é pensar que se sabe quanto pagou por eles; pessoalmente, ele gozaria mais, pelo sentimento, se comprasse cromos de Natal, dos mais piegas, que, porém, não lhe satisfazem tanto a vaidade. Tudo isso pode ser diferente, e o tem sido em muitas sociedades. Em épocas aristocráticas, os homens eram admirados pelo nascimento. Em alguns círculos de Paris, os homens são admirados pelo seu talento artístico ou literário, por estranho que pareça. Numa universidade teuta é possível que um homem seja admirado pelo seu saber. Na Índia os santos são admirados; na China os sábios. O estudo dessas sociedades divergentes demonstra a correção de nossa análise, pois em todas encontramos grande percentagem de homens indiferentes ao dinheiro, contanto que tenham o suficiente para se sustentar; mas que desejam ardentemente a posse dos méritos pelos quais, no seu meio, se conquista o mérito.

(RUSSEL, Bertrand. Ensaios céticos. 2. ed. São Paulo, 1957. p. 67-68). 